\title{
An investigation of the eating attitudes and coping ways with stress among medical students
}

\author{
Esra Doğruelø, Selçuk Kırlı® \\ Department of Psychiatry, Bursa Uludăg University School of Medicine, Bursa, Turkey
}

\begin{abstract}
Objectives: The purpose of the current study is to investigate the eating attitudes, coping ways and their relationships among medical students.

Methods: A total of 100 medical students from all class levels of the medical school (except first and final year undergraduates) consisted of the research sample. Demographic Information Form, Eating Attitude Test and Coping with Stress Scale were filled by participants. SPSS 21.0 was used to analyze the data obtained.

Results: Findings of the study showed no significant differences between abnormal and normal eating attitude groups in terms of demographic variables (gender, age and body mass index, class levels). In addition, there was no significant difference between the groups with regard to avoidance coping score and problem focused coping score. However, there was a significant difference between eating attitude groups in terms of seeking social support score. The mean of social support score is higher in the abnormal eating attitude group.

Conclusions: According to our results, abnormal eating attitude group uses more seeking social support coping than normal eating attitude group.
\end{abstract}

Keywords: Eating attitude, coping ways with stress, medical students

E ating is one of the most important needs for the continuity of life in both humans and animals. Energy needs, social setting, time of day and stress can be counted as an answer of why animals and humans eat [1]. External and internal factors which influence appetite determine what types of food and how much amount of food is consumed by people. Internal factors contain physiological mechanisms of humans affecting appetite and they also include hormones. While food intake is stimulated by neuropeptide-Y, it is reduced by leptin. In addition, various external factors can affect food intake such as social factors (e.g., presence of others) and environmental factors (e.g., food prices) [2].

Alvarenga et al. [3] described eating attitudes as "beliefs, thoughts, feelings, behaviors and relationship with food". Various factors play a role in eating attitudes and also in disturbed eating attitudes which are seen as pioneer of eating disorders [4]. Eating disorders are one of the quite common psychiatric disorders in both Turkey and all around the world [5].

Stress is ineluctable phenomena in modern life [6]. It is prevalently believed that stress can have an impact on eating patterns [7]. Even though the nature of the association between eating disorders and stress is not obviously explained, several empirical researches and clinical observations show the relationship between stress and abnormal eating behavior [8,9]. Moreover, findings about the impact of severity of stress on the eating behavior are controversial. The severity of

Received: August 20, 2019; Accepted: October 23, 2019; Published Online: January 7, 2020

How to cite this article: Doğruel E, Klrl S. An investigation of the eating attitudes and coping ways with stress among medical students. Eur Res $J$ 2021;7(2):196-202. DOI: 10.18621/eurj.607628

Address for correspondence: Esra Doğruel, MS., Bursa Uludă̆ University School of Medicine, Department of Psychiatry, Bursa, Turkey E-mail: esra.dgrl2@gmail.com 
stress can be related with both decreased and increased eating behavior. The researchers have conducted a retrospective survey in United States Marines during combat in order to examine eating attitude of marines in this highly stressful situation. The results showed that when they experienced particularly their initial combat, their food intake decreased [10]. On the other hand, the influence of school examination which is a highly stressful event on eating attitude was investigated [8]. The results have indicated that there was a significant difference between examination day and stress-free day in terms of students' total energy intake. This study revealed that the energy intake increases in the major stressful circumstance.

Studies from different samples have reported that some certain groups of people are at higher risk for eating disorders, such as young adults [11]. Previous studies have suggested that eating disorders among college students in Western countries increase $[12,13]$. A research conducted in Turkish sample has also revealed that eating disorders are quite prevalent in university students [14].

Coping is defined as "the cognitive and behavioral efforts made to master, tolerate, or reduce external and internal demands and conflicts among them" by Folkman and Lazarus [15]. Indeed, it is a factor determining the effect of stress on health [16]. Thus, it is crucial to apprehend individual's coping ways when under stressful life situation. Folkman and Lazarus [15] suggested two ways of coping: problem-focused coping which refers to focusing on managing and changing what the stressor is in person-environment relationship, and emotion-focused coping which refers to focusing on regulating emotional state regarding some stressful circumstance. Additionally, avoidance coping (getting away from stressor) and approach coping (going towards stressor) is another categorization in the literature $[17,18]$.

Although there are a lot of studies examining eating disorders, there have been a few studies investigating the relationship between eating attitude and coping ways with stress so far, especially on medical students whose education is pretty stressful. Several stress such as inability to cope were revealed among medical students in the earlier study [19]. Moreover, the transitional period from pre-clinical training to clinical training was also reported as critical phase creating stress among medical students [20]. This paper attempts to investigate eating attitudes which are indicative factor for eating disorders instead of diagnosing participants with a particular disorder and also to examine coping ways with stress. Additionally, the relationship between eating attitudes and coping ways with stress is examined.

\section{METHODS}

\section{Participants}

The participants were undergraduate medical students in Bursa Uludag University in the 2018-2019 academic year. Participation was based on voluntary. Research inclusion criteria were the absence of any psychiatric disorder and not being international students due to probable cultural differences in eating attitudes. In addition, first year and final year students were excluded from the study. It was considered that first year undergraduates could be stressful because of difficulties in adjustment to the university life such as being away from the home for the first time and final year undergraduates also could be stressful due to preparing Specialty Exam in Medicine (TUS) at the end of the year.

Initially, data was collected from a total of 200 students (110 females and 90 males). The number of participants from each class taking part in the study was determined according to the number of students in the classes. Among these participants, 49 of them were $2^{\text {nd }}$ year, 44 of them were $3^{\text {rd }}$ year, 56 of them were $4^{\text {th }}$ year and 51 of them were $5^{\text {th }}$ year. Thereafter, because the sample was nonclinical and cut off point is not determined for Turkish sample, the students who got $25 \%$ highest score in Eating Attitude Test (comparatively abnormal eating attitudes) and who got $25 \%$ lowest score in Eating Attitude Test (comparatively normal eating attitudes) were determined as research participants as it was done in the past studies [21-23]. Thus, the certain sample size included 100 students ( 27 of them were from 2 nd year, 21 of them were from $3^{\text {rd }}$ year, 26 of them were from 4 th year and 26 of them were from 5th year) in the current study. Their age range was between 18 and 27 years.

\section{Measures and Procedure}

The researcher gave a brief introduction about the 
present study to the participants and ensured confidentiality to them. Besides the Demographic Information Form, two questionnaires were administered, respectively: Eating Attitude Test and Coping with Stress Scale. Participants were asked to fill all items of these questionnaires and they were encouraged to feel free to ask any question. The tests were lasted approximately 15 minutes by each participant. The study was approved by Bursa Uludag University Faculty of Medicine Clinical Research Ethics Committee.

\section{Demographic Information Form}

The researchers developed the form to collect the data describing participants (e.g. sex, age, class level, and so on).

\section{Eating Attitude Test (EAT-40)}

It was developed by Garner and Garfinkel [24]. In the present study, it was used to assess eating attitudes and behaviors of participants. It is a self administered scale consisting of 40 items. Validity and reliability study in Turkey was run by Savaşır and Erol [25]. The cut off score was 30 in the original form, whereas it was not calculated for Turkish sample.

\section{Coping with Stress Scale (CSS)}

This scale was developed based on Folkman and Lazarus' model by Türküm [26]. It is a 5-point Likert type scale and comprises 23 items. Additionally to a single score which is minimum 23 and maximum 115 , there are three subscales: Seeking social support, Problem focused coping and Avoidance. The score obtained from the subscales reflects which coping way is mostly used by individual.

\section{Statistical Analysis}

SPSS (IBM Corp. Released 2012. IBM SPSS Statistics for Windows, Version21.0. Armonk, NY: IBM Corp.) was used to analyze data statistically and $\mathrm{p}<0.05$ was considered statistically significant. Shapiro Wilk test was used to determine the conformity of the variables to normal distribution. Continuous variables were expressed with median (minimum: maximum) and mean \pm standard deviation or mean \pm standard deviation (minimum: maximum) values. In order to express categorical variables, $\mathrm{n}(\%)$ was used. According to the outcomes of normality test,
Mann Whitney $U$ test and Independent samples $t$ test were used to compare two groups. Also, Pearson chisquare test was used to compare categorical variables among groups. The relationship between EAT score and CSS subscale scores were examined by correlation and also Spearman correlation coefficient (rs) was calculated.

\section{RESULTS}

Table 1 shows the distribution of participants in terms of EAT cut off score and Table 2 indicates the distribution of eating attitudes divided into two groups as normal and abnormal eating attitude groups.

Table 3 describes the comparisons of normal and abnormal eating attitude groups in terms of some demographic characteristics. There was no significant difference in terms of gender $(p=0.062)$, age $(p=$ $0.950)$ and BMI $(p=0.877)$.

Table 4 shows that no significant differences in eating groups in terms of class level $(p=0.782)$ and whether to be in the period of pre-clinical and clinical trainig $(p=0.423)$.

\section{Table 1. Distribution of participants according to EAT cut off score}

$(\mathrm{n}=\mathbf{2 0 0})$

Lower than EAT cut off score $\quad 183(91.5 \%)$

Higher than EAT cut off score

$17(8.5 \%)$

EAT total score

$15.42 \pm 8.79(3-47)$

Data are expressed as $\mathrm{n}(\%)$ and mean \pm standard deviation (minimum -maximum). EAT $=$ Eating Attitude Test

Table 2. Distribution of participants as normal and abnormal eating attitudes in terms of EAT scores

(n=100)

Normal eating attitude

$50(50 \%)$

Abnormal eating attitude $50(50 \%)$

EAT total score

$17.59 \pm 11.81(3-47)$

Data are expressed as $\mathrm{n}(\%)$ and mean \pm standard deviation (minimum -maximum). EAT $=$ Eating Attitude Test 
Table 3. Comparisons of eating attitude (EA) groups in terms of gender, age and body mass index (BMI)

\begin{tabular}{lcccc}
\hline & & $\begin{array}{c}\text { Normal EA } \\
(\mathbf{n}=\mathbf{5 0})\end{array}$ & $\begin{array}{c}\text { Abnormal EA } \\
(\mathbf{n}=\mathbf{5 0})\end{array}$ & p-value \\
\hline Gender $(\mathrm{F} / \mathrm{M})$ & & & & \\
& Female & $27(54.0 \%)$ & $36(72.0 \%)$ & $0.062^{\mathrm{a}}$ \\
& Male & $23(46.0 \%)$ & $14(28.0 \%)$ & \\
Age & & $22(19-27)$ & $21(19-24)$ & $0.950^{\mathrm{b}}$ \\
& & $21.34 \pm 1.85$ & $21.20 \pm 1.56$ & $0.877^{\mathrm{b}}$ \\
BMI & $21.80(17-30)$ & $21.90(16-32)$ & \\
\hline
\end{tabular}

Data are expressed as $\mathrm{n}(\%)$ and mean \pm standard deviation (minimum - maximum).

${ }^{\mathrm{a}}$ Chi square test, ${ }^{\mathrm{b}}$ Mann-Whitney U test

Table 4. Comparisons of eating attitude (EA) groups in terms of their class levels

\begin{tabular}{lccc}
\hline & $\begin{array}{c}\text { Normal EA } \\
(\mathbf{n}=\mathbf{5 0})\end{array}$ & $\begin{array}{c}\text { Abnormal EA } \\
(\mathbf{n = 5 0 )}\end{array}$ & p-value \\
\hline \multicolumn{1}{c}{ Class level } & & & \\
$2^{\text {nd }}$ year & $13(26.0 \%)$ & $14(28.0 \%)$ & \\
$3^{\text {rd }}$ year & $9(18.0 \%)$ & $12(24.0 \%)$ & $0.782^{\mathrm{a}}$ \\
$4^{\text {th }}$ year & $15(30.0 \%)$ & $11(22.0 \%)$ & \\
$5^{\text {th }}$ year & $13(26.0 \%)$ & $13(26.0 \%)$ & $0.423^{\mathrm{a}}$ \\
\hline Pre-clinical training & $22(44.0 \%)$ & $26(52.0 \%)$ & \\
Clinical training & $28(56.0 \%)$ & $24(48.0 \%)$ & \\
\hline
\end{tabular}

Data are expressed as n (\%).

${ }^{a}$ Chi square test

Table 5. Comparisons of eating attitude (EA) groups in terms of CSS subscale scores

\begin{tabular}{lccc}
\hline & $\begin{array}{c}\text { Normal EA } \\
(\mathbf{n}=\mathbf{5 0})\end{array}$ & $\begin{array}{c}\text { Abnormal EA } \\
(\mathbf{n}=\mathbf{5 0 )}\end{array}$ & $\boldsymbol{p}$-value \\
\hline Avoidance & $26.50(17-36)$ & $27(15-36)$ & $0.279^{\mathrm{b}}$ \\
& $26.48 \pm 4.55$ & $27.32 \pm 5.35$ & \\
Problem focused & $30(13-37)$ & $31(12-40)$ & $0.155^{\mathrm{b}}$ \\
coping & $28.38 \pm 5.50$ & $29.54 \pm 5.95$ & \\
Seeking social & $22.60 \pm 4.64$ & $25.26 \pm 6.14$ & $\mathbf{0 . 0 1 6}^{\mathrm{e}}$ \\
suppport & $(10-33)$ & $(7-35)$ & \\
\hline
\end{tabular}

Data are expressed as median (minimum:maximum and mean \pm standard deviation and mean \pm standard deviation (minimum:maximum). CSS $=$ Coping with Stress Scale

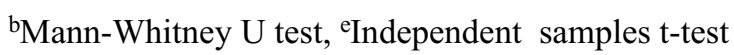


Table 6. The correlation between CSS subscales' scores and EAT score

\begin{tabular}{lcc}
\hline & \multicolumn{2}{c}{ EAT } \\
\hline & $\mathrm{r}_{\mathrm{s}}$ & $\mathrm{p}$ \\
Avoidance & 0.19 & 0.058 \\
Problem focused coping & 0.17 & 0.100 \\
Seeking social support & 0.17 & 0.085 \\
\hline
\end{tabular}

CSS $=$ Coping with Stress Scale, EAT $=$ Eating Attitude Test, $\mathrm{r}_{\mathrm{s}}=$ Spearman correlation coefficient

Table 5 shows that there was not a significant difference between eating attitude groups in terms of avoidance coping score $(p=0.279)$ and problem focused coping score $(p=0.155)$. However, there was a significant difference between eating attitude groups in terms of seeking social support score. The mean of social support score is higher in the abnormal eating attitude group $(p=0.016)$.

Table 6 indicates that no relationship between CSS subscales' scores and EAT score.

\section{DISCUSSION}

Eating attitude is one of the common topics studied by contemporary clinical psychology and psychiatry. In the current study, the objectives were to examine the eating attitudes, to determine coping ways with stress and to reveal the associations between these variables among medical students.

Results of the study indicated no significant differences with regard to demographic variables between abnormal and normal eating attitude groups. Our findings did not offer differences between eating attitude groups in terms of gender and age. Similar to our findings, Khalid et al. [27] reported that there was no significant difference between male and female in terms of the prevalence of disturbed eating attitudes and age. On the other hand, contrary to our findings, there exist some studies suggesting that female students have higher risk of eating disorders than male students [28].

In the current study, no significant difference was found in BMI. This finding is consistent with previous study that has suggested that BMI may be a more significant predictor for risk of eating disorder in younger adolescents compared to young adult women [29]. Also, symptomatic behavior might not be a direct indicator of pathology, especially bulimia nervosa [30], it might explain why abnormal and normal eating attitude groups did not differ from one another in terms of BMI. In addition, abnormal and normal eating attitude groups did not differ from one another according to their class levels and whether to be clinical or pre-clinical training.

Finding from our study suggests that there is significant difference between abnormal eating attitude group and normal eating attitude group in terms of coping ways used under stressful circumstances. Abnormal eating attitude group use more seeking social support than normal eating attitude group. Contrary to our finding, Ball and Lee [31] revealed that eating disordered individuals use less active coping ways including seeking social support. On the other hand, Odacı and Çıkrıkçı [32] found that medical students got the highest score for the seeking social support in the all faculties included in their study. They suggested that it might be due to the fact that their practical classes and more intense curricula can contribute to improve one to one sharing with others among medical students. In this sense, when we consider these two studies' results together, our finding may be interpreted as because abnormal eating attitude group in medical students have difficulties to cope with stress, they try to get benefit from their improved skills during education process and they seek social support.

Results showed that abnormal eating attitude group did not differ from normal eating attitude group in terms of problem-focused coping. Similar to our findings, early study revealed no significant difference in problem-focused coping between eating disorder patients and control subjects [33]. As an alternative explanation for these findings, Odacı and Çıkrıkçı [32] have reported that medical students use more the problem-focused coping way than students in other faculties. They suggested that this may be due to medical students are more resistant than other faculty members.

In the present study, no significant difference was found in avoidant coping between the groups. Odac1 and Ç1krıkçı [32] indicated that medical and dental students use more avoidance strategy compared to the students in other faculties. In this sense, because 
medical students use more avoidance strategy and our research groups comprised of medical students, abnormal and normal eating attitude groups did not differ from one another. In addition, although our finding did not accord with those of Mayhew and Edelmann [34] who reported that avoidant coping is found associated with eating pathology in nonclinical sample; similar to our findings, a study carried out 149 undergraduate students [35] did not reveal association between binge eating and avoidance coping.

After medical students complete their education, they will work to improve human health. Therefore, they should protect primarily their own mental and physical health. Stress is inevitable part of life, but stress management can be improved. Hence, we recommend that stress management workshops can be carried out medical students.

\section{Limitations}

There are also several certain limitations in the current study. Since nonclinical sample was used and EAT scores' range was relatively narrow, findings should be interpreted with these potential limitations in mind. Another limitation was that the research sample consisted of medical students from one university. This makes difficult to generalize the findings to all medical student population. In future study, it will be important to acquire data from different medical faculty students.

Further research should replicate the findings with increased sample size. In addition, students may be rewarded in an effective way to increase their motivation to participate study. For instance, extra credits for their courses can be given.

\section{CONCLUSION}

We concluded that individuals with normal eating attitude group and individuals with abnormal eating attitude do not differentiate in terms of demographic characteristics. Also, abnormal eating attitude group uses more seeking social support coping than normal eating attitude group. Because our research sample involved medical students who are in cooperation regarding to their practical classes, they seek social support to cope with stressors.

\section{Authors' Contribution}

Study Conception: ED, SK; Study Design: ED, SK; Supervision: ED, SK; Funding: ED, SK; Materials: ED, SK; Data Collection and/or Processing: ED; Statistical Analysis and/or Data Interpretation: ED, SK; Literature Review: ED; Manuscript Preparation: ED, SK and Critical Review: ED, SK.

\section{Conflict of interest}

The authors disclosed no conflict of interest during the preparation or publication of this manuscript.

\section{Financing}

The authors disclosed that they did not receive any grant during conduction or writing of this study.

\section{REFERENCES}

1. Levine AS, Billington CJ. Why do we eat? A neural systems approach. Annu Rev Nutr 1997;17:597-619.

2. Popkin BM, Duffey K, Gordon-Larsen P. Environmental influences on food choice, physical activity, and energy balance. Physiol Behav 2005;86:603-13.

3. Alvarenga MS, Scagliusi FB, Philippi ST. Development and validity of the disordered eating attitude scale (DEAS). Percept Mot Skills 2010;110:379-95.

4. Leichner P, Arnett J, Rallo JS, Srikameswaran S, Vulcano B. An epidemiologic study of maladaptive eating attitudes in a Canadian school age population. Int J Eat Disord 1986;5:969-82. 5. Kumcağız H, Şahin C, Alakuş K, Akbaş M. The role of hope and negative thoughts in predicting eating attitudes. IJOESS 2017;8:939-54.

6. Hung C. Coping strategies of primary school teachers in Taiwan experiencing stress because of teacher surplus. Soc Behav Pers 2011;39:1161-74.

7. Wardle J, Gibson EL. Impact of stress on diet: process and implications. In: Stansfield S, Marmot M, editors. Stress and the heart. Psychosocial pathways to coronary heart disease. London: BMJ Publishing Group; 2002:124-49.

8. Michaud C, Kahn JP, Musse N, Burlet C, Nicolas JP, Mejean L. Relationships between a critical life event and eating behavior in high-school students. Stress Med 1990;6:57-64.

9. Strober M. Stressful life events associated with bulimia in anorexia nervosa: empirical findings and theoretical speculations. Int J Eat Disord 1984;3:3-16.

10. Popper R, Smits G, Meiselman HL, Hirsch E. Eating in combat: a survey of U.S. Marines. Mil Med 1989;154:619-23.

11. Seymeur M, Hoerr SL, Huang Y. Inappropriate dieting behaviors and related lifestyle factors in young adults: are college students different? J Nutr Educ 1997;29:21-5.

12. Thorsteinsdottir G, Ulfarsdottir L. Eating Disorders in 
College Students in Iceland. Eur J Psychiat 2008;22:107-15. 13. Hoerr SL, Bokram R, Lugo B, Bivins T, Keast DR. Risk for disordered eating relates to both gender and ethnicity for college students. J Am Coll Nutr 2002;21:307-14.

14. Işı 1 B. [Determining the Eating Disorders in the Students of Uludag University]. Published doctoral dissertation. Uludag University, Bursa, Turkey. 2009. [Article in Turkish]

15. Folkman S, Lazarus RS. An analysis of coping in a middleaged community sample. J Health Soc Behav 1980;21:219-39.

16. Tobin DL, Holroyd KA, Reynolds RV, Wigal JK. The Hierarchical factor structure of the coping strategies inventory. Cogn Ther Res 1989;13:343-61.

17. Billings AG, Moos RH. The role of coping responses and social resources in attenuating the stress of life events. J Behav Med 1981;4:139-57.

18. Roth S, Cohen LJ. Approach, avoidance, and coping with stress. American Psychologist 1986;41:813-9.

19. Shaikh BT, Kahloon A, Kazmı M, Khalid H, Nawaz K, Khan $\mathrm{N}$, et al. Students, stress and coping strategies: a case of Pakistani medical school. Educ Health 2004; 17:346-53.

20. Helmers KF, Danoff D, Steinert Y, Leyton M, Young SN. Stress and depressed mood in medical students, law students, and graduate students at McGill University. Acad Med 1997;72:70814.

21. Aytin N. [Examining the relationship between eating attitude, social problem solving and parental bonding in adolescents]. Unpublished master's thesis. Adnan Menderes University, Aydın, Turkey. 2014. [Article in Turkish]

22. Çakırlı Alşan Z. [The relationship between abnormal eating attitudes and behaviors and family environment self-esteem and perfectionism]. Published master's thesis. Istanbul University, İstanbul, Turkey. 2005. [Article in Turkish]

23. Meyer C, Waller G. The impact of emotion upon eating behavior: the role of subliminal visual processing of threat cues. Int J Eat Disord 1999;25:319-26.

24. Garner DM, Garfinkel PE. The eating attitudes test: an index of the symptoms of anorexia nervosa. Psychol Med 1979;9:2739.

25. Savaşır I, Erol N. Yeme Tutum Testi: Anoreksiya nervoza belirtiler endeksi. Turk Psikoloji Dergisi 1989;7:19-25. [Article in Turkish]

26. Türküm AS. Stresle Başa Çıkma Ölçeğinin Geliştirilmesi: Geçerlik ve Güvenirlik Çalışmaları, Türk Psikolojik Danışma ve Rehberlik Dergisi 2002;2:25-34. [Article in Turkish]

27. Khalid S, Razia ET, Raza MH, Sheikh H, Salman M, Shehzadi N, et al. It's not just a "female issue": eating attitudes and behaviors of Pakistani male and female pharmacy students. Russ Open Med J 2017;6:e0406.

28. Memon AA, Adil SE, Siddiqui EU, Naeem SS, Ali SA, Mehmood K. Eating disorders in medical students of Karachi, Pakistan-a cross-sectional study. BMC Res Notes 2012;5:84.

29. Huon G, Lim J. The emergence of dieting among female adolescents: age, body mass index, and seasonal effects. Int J Eat Disord 2000;28:221-5.

30. Wilson G, Eldredge K. Frequency of binge eating in bulimic patients: diagnostic validity. Int J Eating Disord 1991;10:557-61. 31. Ball K, Lee C. Relationships between psychological stress, coping and disordered eating: a review. Psychol Health 2000;14:1007-35.

32. Odacı H, Çıkrıkçı Ö. University students' ways of coping with stress, life satisfaction and subjective well-being. TOJCE 2012;1:117-30.

33. Troop NA, Holbrey A, Trowler R, Treasure JL. Ways of coping in women with eating disorders. J Nerv Ment Dis 1994;182:535-40.

34. Mayhew R, Edelmann R. Self-esteem, irrational beliefs, and coping strategies in relation to eating problems in a nonclinical population. Pers Indiv Diff 1989;10:581-4.

35. Paxton SJ, Diggens 1. Avoidance coping, binge eating, and depression: an examination of the escape theory of binge eating. Int J Eat Disord 1997;22:83-7. 